\title{
Effect of Surface Nonequilibrium Thermochemistry in Simulation of Carbon Based Ablators
}

\author{
EXTENDED ABSTRACT \\ Yih-Kanq Chen ${ }^{*}$, \\ NASA Ames Research Center, Moffett Field, CA 94035-1000 \\ And \\ Tahir Gökçen ${ }^{\dagger}$ \\ ERC, Inc., NASA Ames Research Center, Moffett Field, CA 94035-1000
}

This study demonstrates that coupling of a material thermal response code and a flow solver using finite-rate gas/surface interaction model provides time-accurate solutions for multidimensional ablation of carbon based charring ablators. The material thermal response code used in this study is the Twodimensional Implicit Thermal Response and Ablation Program (TITAN), which predicts charring material thermal response and shape change on hypersonic space vehicles. Its governing equations include total energy balance, pyrolysis gas momentum conservation, and a three-component decomposition model. The flow code solves the reacting Navier-Stokes equations using Data Parallel Line Relaxation (DPLR) method. Loose coupling between material response and flow codes is performed by solving the surface mass balance in DPLR and the surface energy balance in TITAN. Thus, the material surface recession is predicted by finite-rate gas/surface interaction boundary conditions implemented in DPLR, and the surface temperature and pyrolysis gas injection rate are computed in TITAN. Two sets of gas/surface interaction chemistry between air and carbon surface developed by Park and Zhluktov, respectively, are studied. Coupled fluid-material response analyses of stagnation tests conducted in NASA Ames Research Center arc-jet facilities are considered. The ablating material used in these arc-jet tests was a Phenolic Impregnated Carbon Ablator (PICA). Computational predictions of in-depth material thermal response and surface recession are compared with the experimental measurements for stagnation cold wall heat flux ranging from 107 to $1100 \mathrm{~W} / \mathrm{cm}^{2}$.

\section{Nomenclature}

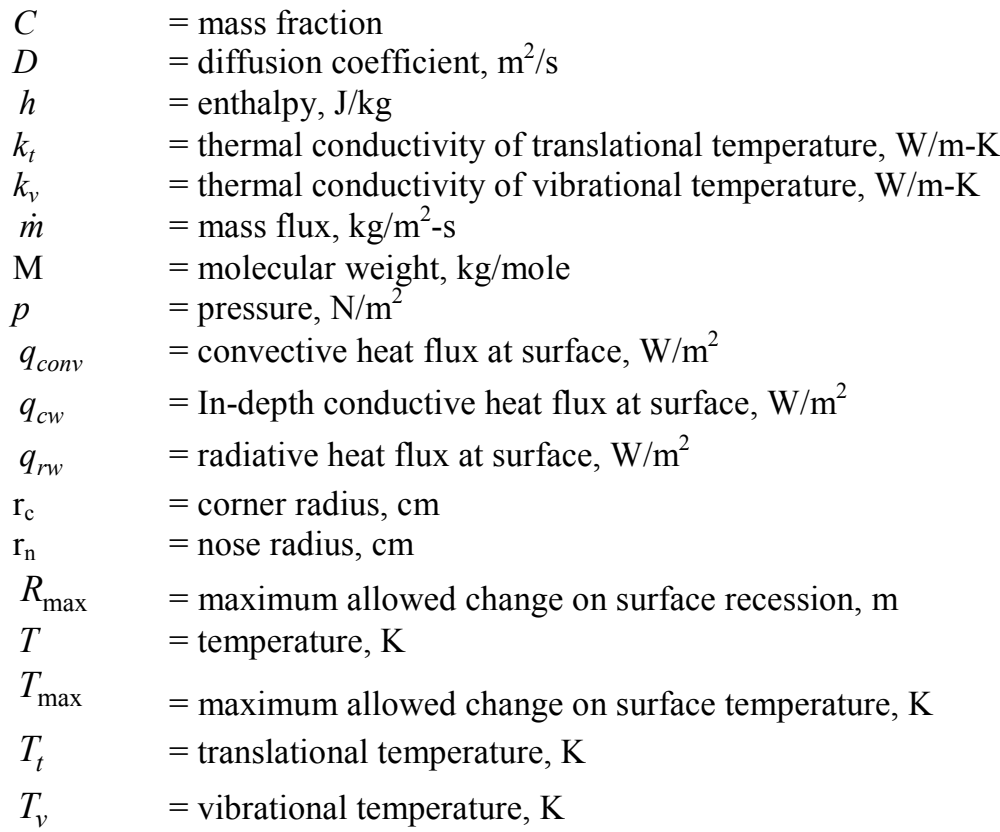

\footnotetext{
* Aerospace Engineer, Aerothermodynamics Branch, MS 230-2, Member AIAA.

${ }^{\dagger}$ Senior Research Scientist, ERC, Inc., Associate Fellow AIAA.
} 


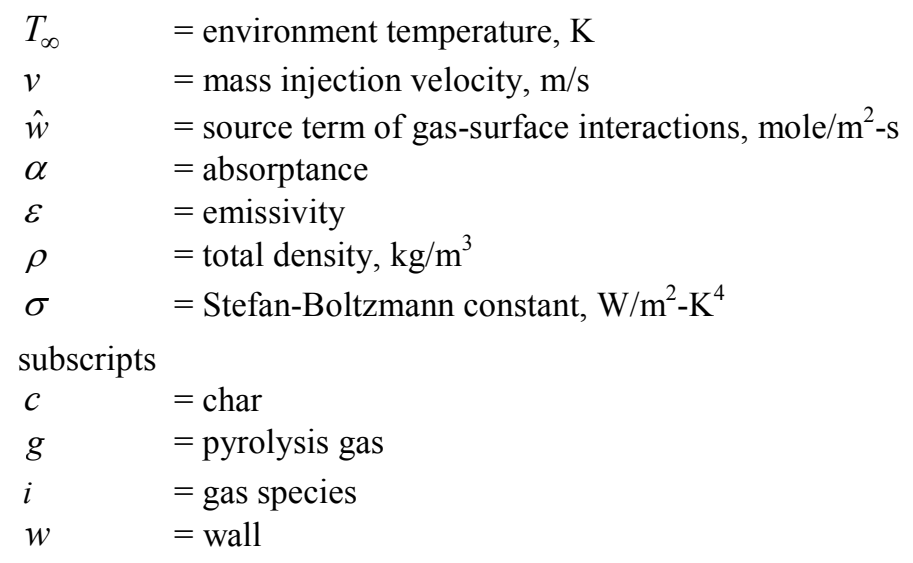

\section{Introduction}

Vehicles designed for Earth entry at superorbital velocities, as well as those designed for ballistic entry at orbital velocities, typically use thermal protection system (TPS) materials that pyrolyze and ablate at high temperature for mass-efficient rejection of the aerothermal heat load. For design and sizing of ablating TPS materials, it is imperative to have reliable numerical procedures which can accurately compute both the aerothermal environments and the material surface ablation and internal thermal response. It has been demonstrated that accurate prediction of ablative heat flux also requires fliuid-solid shape change coupling simulation. ${ }^{1}$ In our previous fluid-solid shape change coupling computations, the ablative carbon surface was assumed to be at chemical equilibrium. ${ }^{2}$ Chemical equilibrium assumption is good for many space entry applications, but may not be true for all conditions. Additionally, the aerothermal environments computed by Data Parallel Line Relaxation method (DPLR) ${ }^{3}$ were those for a fully catalytic non-ablating surface. Thus, an engineering correlation with blowing reduction parameter had to be introduced in the Two-dimensional Implicit Thermal Response and Ablation program (TITAN) ${ }^{4}$ simulation to take into account the effect of mass injection on reduction of convective heat flux. A mass transfer coefficient also had to be defined based on the heat transfer coefficient under the assumption of relatively thin boundary layer for the computation of char recession rate.

The purpose of this paper is to present a new TITAN-DPLR coupling simulation system and its applications to carbon based charring ablators. The boundary condition with general finite-rate chemistry for gas/surface interactions recently implemented in the DPLR code by MacLean ${ }^{5}$ is used to predict char mass injection rate. Thus, surface thermal chemistry coupling is also introduced in this simulation system, in addition to surface shape change coupling. In this simulation system, the surface species mass balance is performed in DPLR, and the surface energy balance is performed in TITAN. The chemical equilibrium assumption can then be removed. The hot-wall ablating convective heat flux is directly computed in DPLR based on the surface temperature and pyrolysis gas injection rate computed in TITAN. The blowing reduction correlation is no longer needed in the material response simulation. Two sets of finite-rate gas/surface interaction chemistry between air and carbon surface are studied. They were developed by Park ${ }^{6}$ and Zhluktov, ${ }^{7}$ respectively. Coupled fluid-material response analyses of stagnation tests conducted in NASA Ames Research Center arc-jet facilities are performed. The ablating material used in these arcjet tests was a Phenolic Impregnated Carbon Ablator (PICA). ${ }^{8}$ Computational predictions of in-depth material thermal response and surface recession are compared with the experimental measurements for stagnation cold wall heat fluxes from 100 to $1100 \mathrm{w} / \mathrm{cm}^{2}$.

\section{Surface Thermal Chemistry Coupling}

The interface between a TPS material and its surrounding flow field can be defined by solving species mass conservation and energy balance equations. Species mass conservation at the surface of TPS material is written as: ${ }^{9}$

$$
-\rho D_{i} \nabla C_{i}+\rho v_{w} C_{i}=M_{i} \hat{w}_{i}+\dot{m}_{g} C_{i, g}
$$

The first term on the left-hand side is mass transfer through diffusion, and the second term is mass transfer due to convection. On the right-hand side are the source terms due to gas-surface interaction and pyrolysis gas injection. Based on global mass balance at the surface, the following equation for the total mass blowing rate is expressed: 


$$
\rho v_{w}=\dot{m}_{c}+\dot{m}_{g}
$$

The total convective heat flux to the surface for the flow field with two-temperature model is given as:

$$
q_{c o n v}=-k_{t} \nabla T_{t}-k_{v} \nabla T_{v}+\sum h_{i} \rho D_{i} \nabla C_{i} .
$$

Energy conservation equation at the surface is written as

$$
q_{c o n v}+\dot{m}_{c}\left(h_{c}-h_{w}\right)+\dot{m}_{g}\left(h_{g}-h_{w}\right)+\alpha_{w} q_{r w}-\sigma \varepsilon_{w}\left(T_{w}^{4}-T_{\infty}^{4}\right)-q_{c w}=0
$$

The first term in Equation (4) is the total convective heat flux, the second and third terms represent the heat of ablation, the fourth and fifth terms are radiation absorption and emission, respectively, and the final term is the rate of heat conduction into the TPS material.

To obtain the solutions for Equations (1) to (4) requires computations of thermal and species diffusion rates of flow field at the surface as well as thermal diffusion and pyrolysis gas injection rates of TPS material at the surface. In a strongly coupled simulation, the governing equations for both fluid and solid are solved simultaneously along with Equations (1) through (4). However, for many simulations, flow solver and material response code are two independent programs, and a loosely coupled simulation needs to be applied. In a loosely coupled simulation, the governing equations for fluid and solid are solved separately, and Equations (1) to (4) have to be solved either in the flow code or in the material response code. Thus, communication between two codes needs to be established for exchanging information on surface thermal chemistry and shape change. If the material surface is at chemical equilibrium, both the mass and energy conservation equations at the surface can be performed in the material simulation code as described in our previous work. For a chemical equilibrium surface, the chemical species at the surface are determined by using a chemical equilibrium code, such as $\mathrm{ACE}^{10}$ and MAT. ${ }^{11}$ In our chemical equilibrium analyses, the hot wall ablating heat flux was estimated from the cold wall non-ablating heat flux using an engineering correlation with a blowing reduction parameter. Also, species mass transfer rate was assumed to be proportional to heat transfer rate based on a constant Lewis number. Under these assumptions, the surface thermal chemistry coupling is not required, and only shape change information has to be exchanged between flow solver and material response code to correctly predict the aerothermal environments and material thermal response. For a general finite-rate surface boundary condition, the approach taken here is having the species mass conservation equation solved with flow-field governing equations and total energy balance equation solved with solid material governing equations. Surface thermal chemistry and shape change have to be shared between flow solver and material solver in a time lagged manner. The schematic diagram in Figure 1 depicts how this loosely coupled simulation is performed. This simulation must be time accurate and starts from the material response simulation code using the boundary conditions of cold wall non-ablating convective heat flux and pressure estimated based on initial free stream conditions. As the maximum surface temperature change or surface recession exceeds the predetermined value, material response computation is temporarily put in a waiting mode and the latest predicted surface temperature and pyrolysis gas injection rates are used as the boundary conditions in performing a flow field simulation. The pyrolysis gas is assumed to be at chemical equilibrium before injected into the adjacent air. This assumption was proved to be reasonable for conditions studied in this paper. ${ }^{12}$ The computational grid system for flow field is reconstructed based on the shape change predicted by the material response code, and the free stream conditions are also updated according to the flight trajectory or arc heater condition. Each flow simulation is a steady-state computation. When the steady-state flow solution is obtained, the time-dependent material response simulation is resumed using the newly predicted surface heat flux, pressure, enthalpy, and char mass injection rate as the boundary conditions. Again material response simulation continues until maximum surface temperature change or surface recession exceeds the maximum allowed value. This process repeats until the end of flight trajectory or arc-jet exposure. 


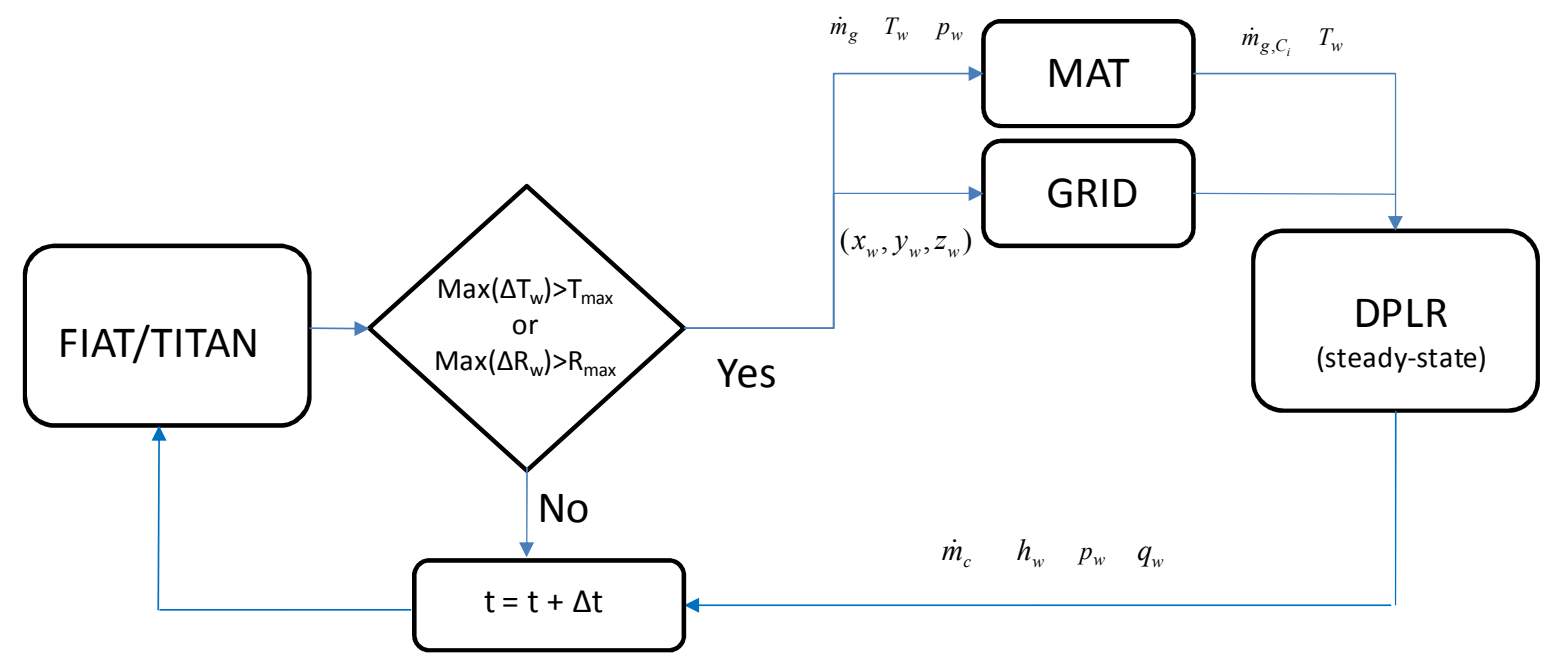

Figure 1. Surface thermochemistry and shape change coupling between FIAT/TITAN and DPLR.

\section{Chemistry Models}

Two sets of gas/surface interaction model between air and carbon surface are studied in this work. The first set was developed by Park ${ }^{6}$ and the second set was developed by Zhluktov. ${ }^{7}$ In this study, the nitridation reaction in the original Park's model is replaced by the nitrogen recombination reaction to be consistent with the observation in the arc-jet tests using pure nitrogen gas. Zhluktov's model is more sophisticated as compared with Park's. In Zhluktov's model, the numbers of empty surface sites, $\mathrm{E}(\mathrm{s})$, and sites occupied by oxygen, $\mathrm{O}(\mathrm{s})$, or nitrogen, $\mathrm{N}(\mathrm{s})$, are considered to predict both the forward and backward reaction rates. Park's model uses an engineering approach considering only the forward reaction. Here $\mathrm{C}(\mathrm{b})$ represents the solid carbon species. The gas/surface reactions used in this study are listed below, and their rates can be found in Refs 6, 7, and 9:

Modified Park:

$\# 1 \mathrm{O}+\mathrm{C}(\mathrm{b}) \rightarrow \mathrm{CO}$

$\# 2 \mathrm{O}_{2}+2 \mathrm{C}(\mathrm{b}) \rightarrow 2 \mathrm{CO}$

$\# 3 \quad 2 \mathrm{~N} \rightarrow \mathrm{N}_{2}$

$\# 4 \quad 3 \mathrm{C}(\mathrm{b}) \rightarrow \mathrm{C}_{3}$

$\# 5 \quad \mathrm{C}_{3} \rightarrow 3 \mathrm{C}(\mathrm{b})$

Zhluktov:

\#1 $\mathrm{O}+\mathrm{E}(\mathrm{s}) \leftrightarrow \mathrm{O}(\mathrm{s})$

\#2 $2 \mathrm{O}(\mathrm{s}) \leftrightarrow \mathrm{O}_{2}+2 \mathrm{E}(\mathrm{s})$

\#3 $\mathrm{O}_{2}+\mathrm{E}(\mathrm{s}) \leftrightarrow \mathrm{O}+\mathrm{O}(\mathrm{s})$

\#4 $\quad \mathrm{CO}_{2}+\mathrm{E}(\mathrm{s}) \leftrightarrow \mathrm{CO}+\mathrm{O}(\mathrm{s})$

\#5 $\mathrm{O}(\mathrm{s} 1)+\mathrm{C}(\mathrm{b}) \leftrightarrow \mathrm{CO}+\mathrm{E}(\mathrm{s} 1)$

\#6 $\mathrm{O}+\mathrm{O}(\mathrm{s})+\mathrm{C}(\mathrm{b}) \leftrightarrow \mathrm{CO}_{2}+\mathrm{E}(\mathrm{s})$

\#7 $\quad 2 \mathrm{O}(\mathrm{s})+\mathrm{C}(\mathrm{b}) \leftrightarrow \mathrm{CO}_{2}+2 \mathrm{E}(\mathrm{s})$

$\# 8 \quad \mathrm{C}+\mathrm{E}(\mathrm{s}) \leftrightarrow \mathrm{E}(\mathrm{s})+\mathrm{C}(\mathrm{b})$

\#9 $\quad \mathrm{C}_{2}+2 \mathrm{E}(\mathrm{s}) \leftrightarrow 2 \mathrm{E}(\mathrm{s})+2 \mathrm{C}(\mathrm{b})$

$\# 10 \quad \mathrm{C}_{3}+3 \mathrm{E}(\mathrm{s}) \leftrightarrow 3 \mathrm{E}(\mathrm{s})+3 \mathrm{C}(\mathrm{b})$

$\# 11 \quad \mathrm{~N}+\mathrm{E}(\mathrm{s}) \leftrightarrow \mathrm{N}(\mathrm{s})$

$\# 12 \quad \mathrm{~N}_{2}+\mathrm{E}(\mathrm{s}) \leftrightarrow \mathrm{N}+\mathrm{N}(\mathrm{s})$

Marschall developed a general formulation for finite-rate gas and surface interactions. ${ }^{13}$ The DPLR code was enhanced by MacLean based on Marschall's work to solve the surface species mass balance equation for the finite- 
rate gas surface reactions. The detail of his implementation can be found in Ref. 5. All flow simulations presented in this work are performed using this version of DPLR code.

There are twenty two gas phase chemical species used in this study for the simulation of PICA and air-Argon interactions. None of the ion species are considered. The chemical species are $\mathrm{CO}_{2}, \mathrm{CO}, \mathrm{N}_{2}, \mathrm{O}_{2}, \mathrm{NO}, \mathrm{C}_{2}, \mathrm{C}_{3}, \mathrm{CN}, \mathrm{H}_{2}$, $\mathrm{HCN}, \mathrm{C}, \mathrm{N}, \mathrm{O}, \mathrm{H}, \mathrm{CH}, \mathrm{CH}_{2}, \mathrm{C}_{2} \mathrm{H}, \mathrm{C}_{2} \mathrm{H}_{2}, \mathrm{C}_{4}, \mathrm{C}_{3} \mathrm{H}, \mathrm{C}_{4} \mathrm{H}$, and Ar. These species were selected based on the chemical equilibrium computation for a PICA/air-Argon system. Their enthalpy makes up more than $95 \%$ of total gas enthalpy as compared with the baseline 119 chemical equilibrium species model developed by Orion TPS Advanced Development Project. ${ }^{14}$ The gas phase chemical reactions considered in the simulations are

$$
\begin{array}{ll}
\# 1 & \mathrm{CO}_{2}+\mathrm{M} \leftrightarrow \mathrm{CO}+\mathrm{O}+\mathrm{M} \\
\# 2 & \mathrm{CO}+\mathrm{M} \leftrightarrow \mathrm{C}+\mathrm{O}+\mathrm{M} \\
\# 3 & \mathrm{~N}_{2}+\mathrm{M} \leftrightarrow \mathrm{N}+\mathrm{N}+\mathrm{M} \\
\# 4 & \mathrm{O}_{2}+\mathrm{M} \leftrightarrow \mathrm{O}+\mathrm{O}+\mathrm{M} \\
\# 5 & \mathrm{NO}+\mathrm{M} \leftrightarrow \mathrm{N}+\mathrm{O}+\mathrm{M} \\
\# 6 & \mathrm{C}_{2}+\mathrm{M} \leftrightarrow \mathrm{C}+\mathrm{C}+\mathrm{M} \\
\# 7 & \mathrm{C}_{3}+\mathrm{M} \leftrightarrow \mathrm{C}_{2}+\mathrm{C}+\mathrm{M} \\
\# 8 & \mathrm{CN}+\mathrm{M} \leftrightarrow \mathrm{C}+\mathrm{N}+\mathrm{M} \\
\# 9 & \mathrm{H}_{2}+\mathrm{M} \leftrightarrow \mathrm{H}+\mathrm{H}+\mathrm{M} \\
\# 10 & \mathrm{~N}_{2}+\mathrm{Ar} \leftrightarrow \mathrm{N}+\mathrm{N}+\mathrm{Ar} \\
\# 11 & \mathrm{O}_{2}+\mathrm{Ar} \leftrightarrow \mathrm{O}+\mathrm{O}+\mathrm{Ar} \\
\# 12 & \mathrm{NO}+\mathrm{Ar} \leftrightarrow \mathrm{N}+\mathrm{O}+\mathrm{Ar} \\
\# 13 & \mathrm{NO}+\mathrm{O} \leftrightarrow \mathrm{O}_{2}+\mathrm{N} \\
\# 14 & \mathrm{~N}_{2}+\mathrm{O} \leftrightarrow \mathrm{NO}+\mathrm{N} \\
\# 15 & \mathrm{CO}+\mathrm{O} \leftrightarrow \mathrm{O}_{2}+\mathrm{C} \\
\# 16 & \mathrm{CO}+\mathrm{O} \leftrightarrow \mathrm{O}_{2}+\mathrm{CO} \\
\# 17 & \mathrm{CO}+\mathrm{C} \leftrightarrow \mathrm{C}_{2}+\mathrm{O} \\
\# 18 & \mathrm{CO}+\mathrm{N} \leftrightarrow \mathrm{CN}+\mathrm{O} \\
\# 19 & \mathrm{~N}_{2}+\mathrm{C} \leftrightarrow \mathrm{CN}+\mathrm{N} \\
\# 20 & \mathrm{CN} \mathrm{O} \leftrightarrow \mathrm{NO}+\mathrm{C} \\
\# 21 & \mathrm{CN}+\mathrm{C} \leftrightarrow \mathrm{C}_{2}+\mathrm{N} \\
\# 22 & \mathrm{HCN}+\mathrm{H} \leftrightarrow \mathrm{CN}+\mathrm{H}_{2} \\
\# 23 & \mathrm{CH}+\mathrm{M} \leftrightarrow \mathrm{C}+\mathrm{H}+\mathrm{M} \\
\# 24 & \mathrm{CH}_{2}+\mathrm{M} \leftrightarrow \mathrm{C}+\mathrm{H}_{2}+\mathrm{M} \\
\# 25 & \mathrm{CH}_{2}+\mathrm{M} \leftrightarrow \mathrm{CH}+\mathrm{H}+\mathrm{M} \\
\# 26 & \mathrm{C}_{2} \mathrm{H}+\mathrm{M} \leftrightarrow \mathrm{C}_{2}+\mathrm{H}+\mathrm{M} \\
\# 27 & \mathrm{C}_{2} \mathrm{H}_{2}+\mathrm{M} \leftrightarrow \mathrm{C}_{2} \mathrm{H}+\mathrm{H}+\mathrm{M} \\
\# 28 & \mathrm{C}_{2}+\mathrm{C}_{2} \leftrightarrow \mathrm{C}_{3}+\mathrm{C} \\
\# 29 & \mathrm{C}_{2}+\mathrm{H}_{2} \leftrightarrow \mathrm{C}_{2} \mathrm{H}+\mathrm{H} \\
\# 30 & \mathrm{CH}_{2}+\mathrm{C} \leftrightarrow \mathrm{CH}+\mathrm{CH} \\
\# 31 & \mathrm{CH}_{2}+\mathrm{CH} \mathrm{CH}_{2} \leftrightarrow \mathrm{C}_{2} \mathrm{H}_{2}+\mathrm{H}_{2} \\
\# 32 & \mathrm{CH}_{2}+\mathrm{C} \leftrightarrow \mathrm{C}_{2} \mathrm{H}+\mathrm{H} \\
\# 33 & \mathrm{CH}_{2}+\mathrm{C}_{2} \mathrm{H} \leftrightarrow \mathrm{CH}+\mathrm{C}_{2} \mathrm{H}_{2} \\
\# 34 & \mathrm{CH}+\mathrm{CH} \leftrightarrow \mathrm{C}_{2} \mathrm{H}+\mathrm{H} \\
\# 35 & \mathrm{CH}+\mathrm{C}_{2} \mathrm{H} \leftrightarrow \mathrm{C}_{2} \mathrm{H}_{2}+\mathrm{C} \\
\# 36 & \mathrm{CH}_{2}+\mathrm{CH} \mathrm{CH}_{2} \leftrightarrow \mathrm{C}_{2} \mathrm{H}_{2}+\mathrm{H}+\mathrm{H} \\
\# 37 & \mathrm{C}_{2}+\mathrm{C}_{2}+\mathrm{M} \leftrightarrow \mathrm{C}_{4}+\mathrm{M} \\
\# 38 & \mathrm{C}+\mathrm{CH} \leftrightarrow \mathrm{C}_{2}+\mathrm{H} \\
\# 39 & \mathrm{C}+\mathrm{C}_{2} \mathrm{H} \leftrightarrow \mathrm{C}_{3}+\mathrm{H} \\
\# 40 & \mathrm{C}_{2}+\mathrm{CH} \leftrightarrow \mathrm{C}_{3}+\mathrm{H} \\
\# 41 & \mathrm{C}_{2}+\mathrm{C}_{2} \mathrm{H} \leftrightarrow \mathrm{C}_{4}+\mathrm{H} \\
\# 42 & \mathrm{CH}_{\mathrm{H}}+\mathrm{H} \leftrightarrow \mathrm{C}+\mathrm{H}_{2} \\
\# 43 & \mathrm{CH}_{2}+\mathrm{H} \leftrightarrow \mathrm{CH}+\mathrm{H}_{2} \\
\# 44 & \mathrm{C}_{2} \mathrm{H}+\mathrm{C}_{2} \mathrm{H} \leftrightarrow \mathrm{C}_{2} \mathrm{H}_{2}+\mathrm{C}_{2} \\
\# 45 & \mathrm{C}+\mathrm{C}_{2} \mathrm{H}_{2} \leftrightarrow \mathrm{C}_{3} \mathrm{H}+\mathrm{H} \\
&
\end{array}
$$




$$
\begin{array}{ll}
\# 46 & \mathrm{C}_{2}+\mathrm{C}_{2} \mathrm{H}_{2} \leftrightarrow \mathrm{C}_{4} \mathrm{H}+\mathrm{H} \\
\# 47 & \mathrm{C}_{2}+\mathrm{C}_{4} \mathrm{H} \leftrightarrow \mathrm{C}_{2} \mathrm{H}+\mathrm{C} 4 \\
\# 48 & \mathrm{C}_{2} \mathrm{H}+\mathrm{C}_{2} \mathrm{H} \leftrightarrow \mathrm{C}_{4} \mathrm{H}+\mathrm{H} \\
\# 49 & \mathrm{C}_{3} \mathrm{H}+\mathrm{H} \leftrightarrow \mathrm{C}_{3}+\mathrm{H}_{2} \\
\# 50 & \mathrm{C}_{4} \mathrm{H}+\mathrm{H} \leftrightarrow \mathrm{C}_{4}+\mathrm{H}_{2} \\
\# 51 & \mathrm{H}+\mathrm{C}_{4}+\mathrm{M} \leftrightarrow \mathrm{C}_{2} \mathrm{H}+\mathrm{M} \\
\# 52 & \mathrm{CH}+\mathrm{CH} \leftrightarrow \mathrm{C}_{2}+\mathrm{H}+\mathrm{H} \\
\# 53 & \mathrm{C}_{2} \mathrm{H}+\mathrm{H}_{2} \leftrightarrow \mathrm{C}_{2} \mathrm{H}_{2}+\mathrm{H}
\end{array}
$$

The reaction rates for reactions \#1-22 are taken from the work of Olynick et al. ${ }^{15}$ for Stardust earth entry simulation. The rates for reactions \#23-36 are taken from Gökçen' ${ }^{16}$ paper for simulations of Titan atmosphere entry. The rates for reactions \#37-53 are taken from the study of Kruse et al. ${ }^{17}$ for high-temperature pyrolysis of Acetylene.

\section{Results}

The computations presented in this section focus on the analysis of surface recession and in-depth thermal response for the PICA heat-shield material. Model validation is accomplished by comparison of predictions with data from seven selected arc-jet tests conducted over a range of stagnation heat flux and pressures ranging from 107 $\mathrm{W} / \mathrm{cm}^{2}$ at $2.3 \mathrm{kPa}$ to $1100 \mathrm{~W} / \mathrm{cm}^{2}$ at $84 \mathrm{kPa}$. The test conditions for these seven test cases are listed in Table 1 . Figure 2 shows the model shape used in these tests. The nose radius equals to the model diameter, and the sides are cylindrical. This is so called "iso-q" geometry $\left(r_{n}=5.08 \mathrm{~cm}\right.$, and $\left.r_{c} / r_{n}=1 / 16\right)$.

Table 1: Seven arc-jet cases selected for detailed analysis.

\begin{tabular}{llll}
\hline Case number & $\begin{array}{l}\text { Stagnation Point heat flux, } \\
\mathrm{W} / \mathrm{cm}^{2}\end{array}$ & $\begin{array}{l}\text { Stagnation point pressure, } \\
\mathrm{kPa}\end{array}$ & $\begin{array}{l}\text { Exposure time, } \\
\mathrm{s}\end{array}$ \\
\hline 1 & 107 & 2.3 & 55 \\
2 & 169 & 5.0 & 60 \\
3 & 246 & 8.5 & 42 \\
4 & 395 & 17.2 & 34 \\
5 & 552 & 27.3 & 30 \\
6 & 744 & 31.0 & 27 \\
7 & 1102 & 84.4 & 10 \\
\hline \hline
\end{tabular}




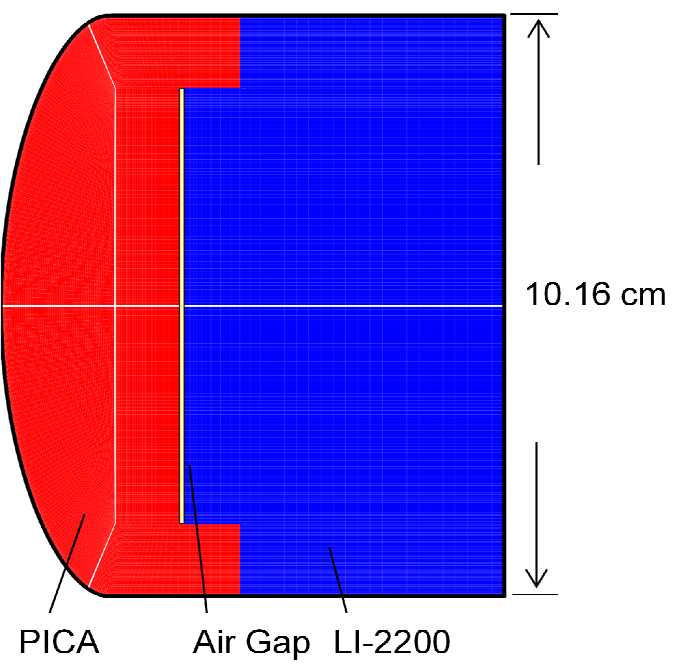

Figure 2. Model geometry and material map.

Figures $3 \mathrm{a}$ and $3 \mathrm{~b}$ present the predicted histories of mass injection rates, heat flux, and temperature at stagnation point for test case 4 using modified Park's surface chemistry. Char mass injection rate and surface heat flux are predicted by DPLR (red lines). Pyrolysis gas mass injection rate and surface temperature are predicted by TITAN (blue lines). The distributions of mass injection rates, heat flux, and temperature along the model surface at the end of exposure time $(\mathrm{t}=34 \mathrm{~s})$ are shown in Figs. $4 \mathrm{a}$ and $4 \mathrm{~b}$. The predicted stagnation-point char mass injection rate is almost identical to data (symbol), which is the measured stagnation point recession multiplied by char density and divided by exposure time. Figure $4 \mathrm{c}$ shows major species mass fractions $\left(\mathrm{CO}, \mathrm{NO}, \mathrm{C}_{3}, \mathrm{H}_{2}, \mathrm{~N}_{2}, \mathrm{~N}, \mathrm{O}\right.$, and $\mathrm{H}$ ) along stagnation stream line. The comparison of in-depth thermal response at various depths between computation (black lines) and TC data (red lines) is presented in Fig. 5. The thermocouple locations within arc-jet models are listed in Table 2. The TC locations for case 4 follow Option B. The agreement between TC data and computation is very good.

The comparison of stagnation point heat flux computed based on different surface chemistry models is shown in Fig. 6a. The predictions using modified Park's model (squares) agree well with the chemical equilibrium surface model with blowing reduction parameter equal to 0.5 (circles). The heat fluxes predicted using Zhluktov's surface chemistry (triangles) appear to be lower than those using Park's model at high heating conditions (cases 4-7). Figure $6 \mathrm{~b}$ is the comparison of stagnation-point char mass injection rates. Generally speaking, char recession rates computed using Modified Park's model are in excellent agreement with data except case 7, in which the prediction is about $20 \%$ below the measurement. Zhluktov's surface chemistry generally under-predicts char recession rates for all the seven cases.

In our proposed paper, the computations using both Park's and Zhluktov's air-carbon interaction models for all seven cases will be presented. The detailed comparisons between current finite-rate approach and the chemical equilibrium approach adopted in our previous paper ${ }^{3}$ will also be discussed.

Table 2: Thermocouple locations within arc-jet models.

\begin{tabular}{llll}
\hline \hline & Axial depth, & $\mathrm{cm}$ & \\
\hline TC number & Option A & Option B & Option C \\
\hline 1 & 0.381 & 0.508 & 0.635 \\
2 & 0.762 & 0.889 & 1.016 \\
3 & 1.143 & 1.270 & 1.397 \\
4 & 1.524 & 1.651 & 1.778 \\
5 & 3.048 & 3.048 & 3.048 \\
\hline \hline
\end{tabular}




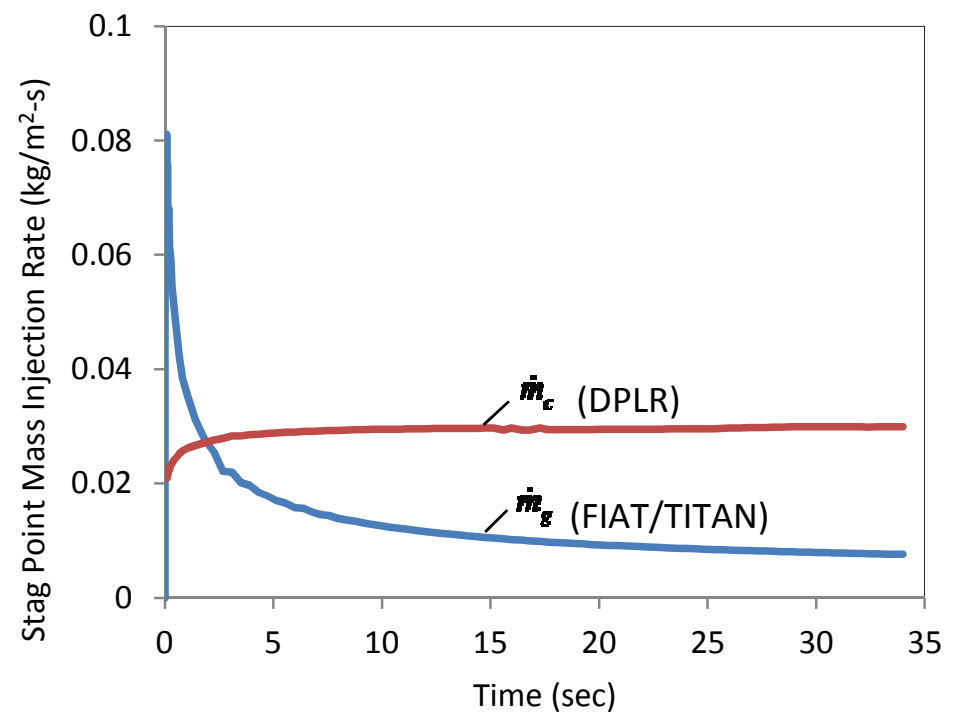

Figure 3a: Stagnation point mass injection rates for case 4 using Park's model.

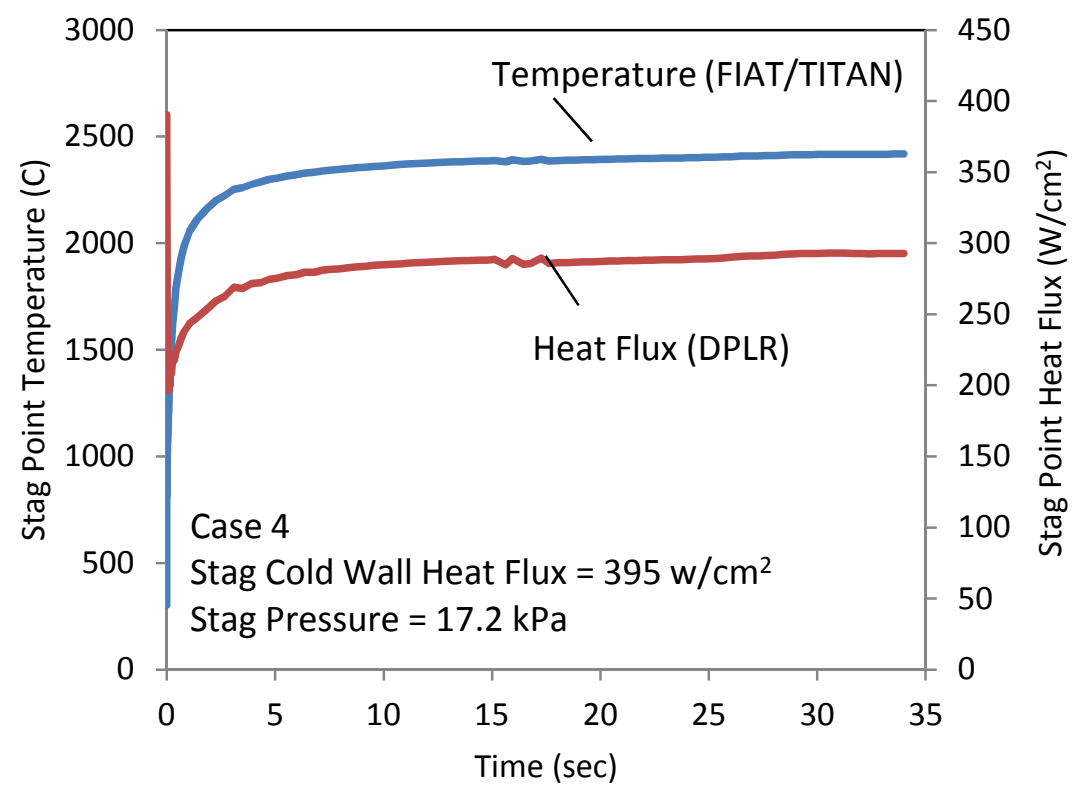

Figure 3b: Stagnation point heat flux and temperature for case 4 using Park's model. 


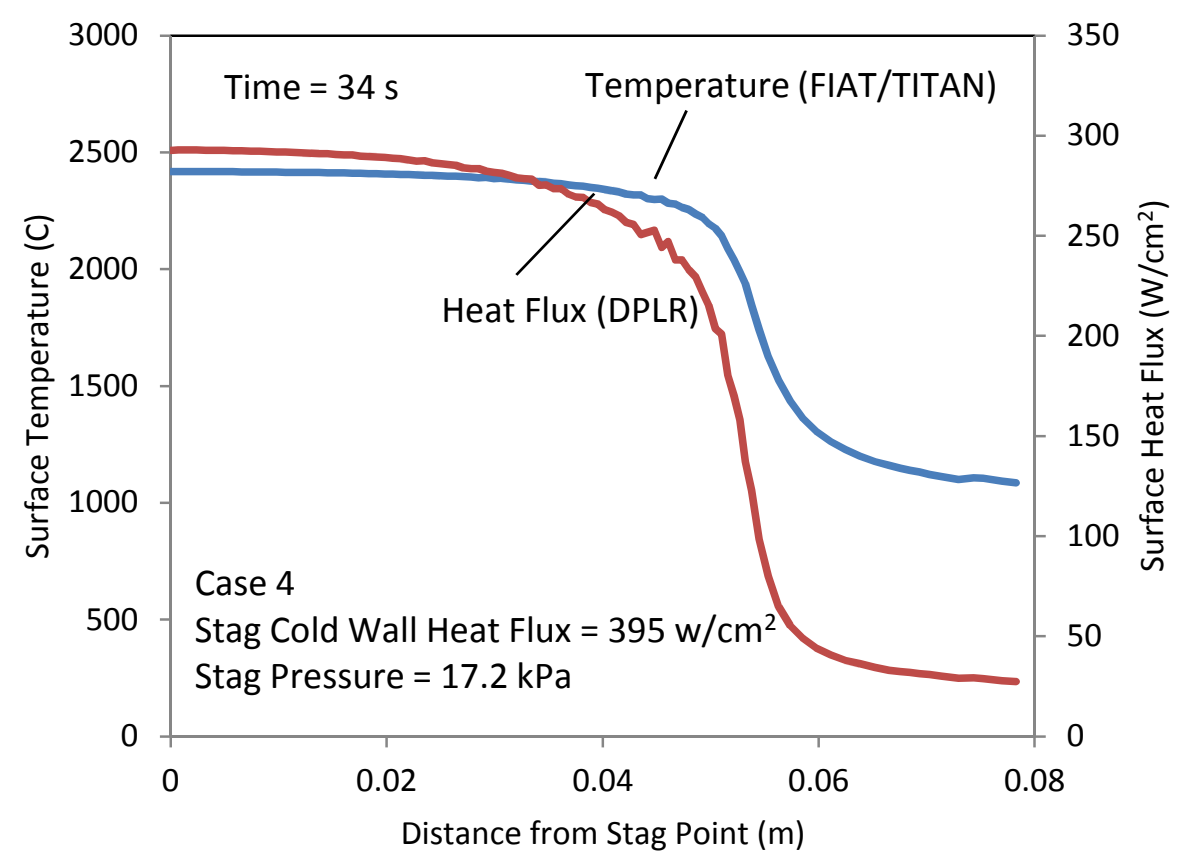

Figure 4a: Surface temperature and heat flux distributions using Park's model for case 4.

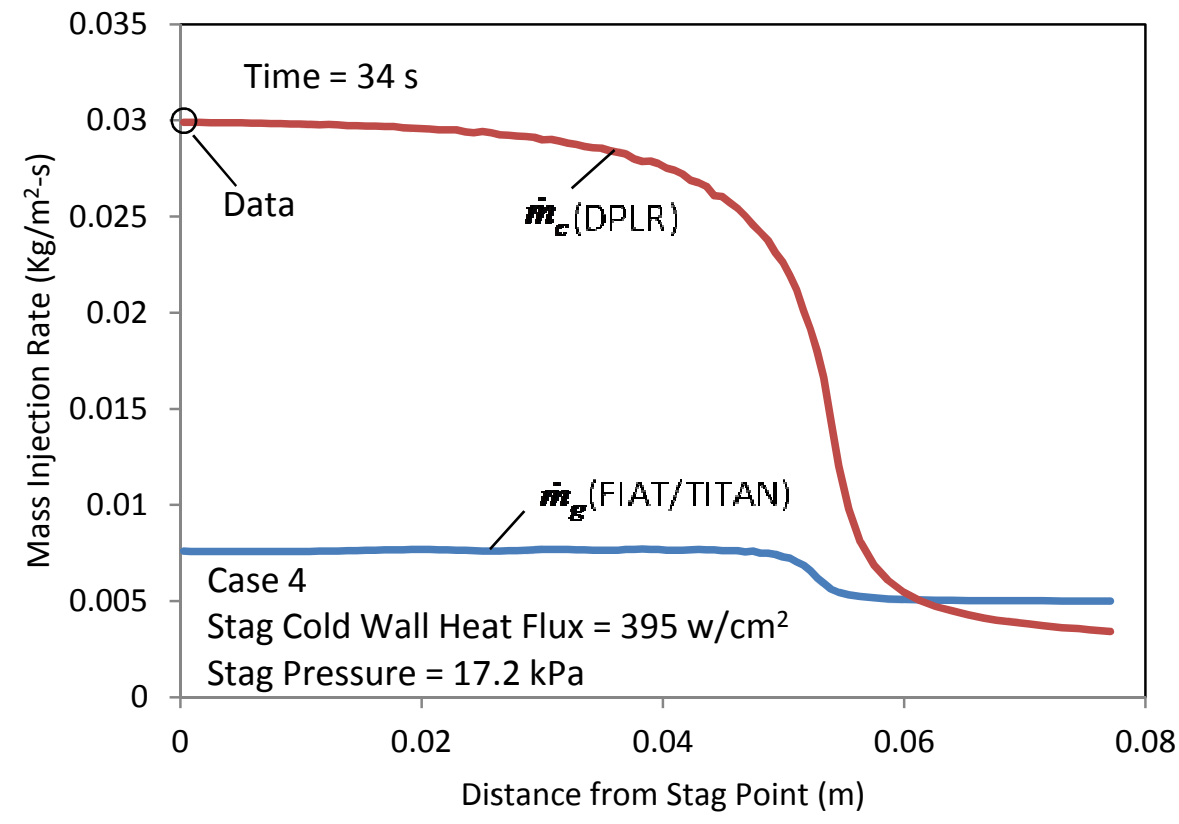

Figure 4b: Mass injection rate distributions using Park's model for case 4. 


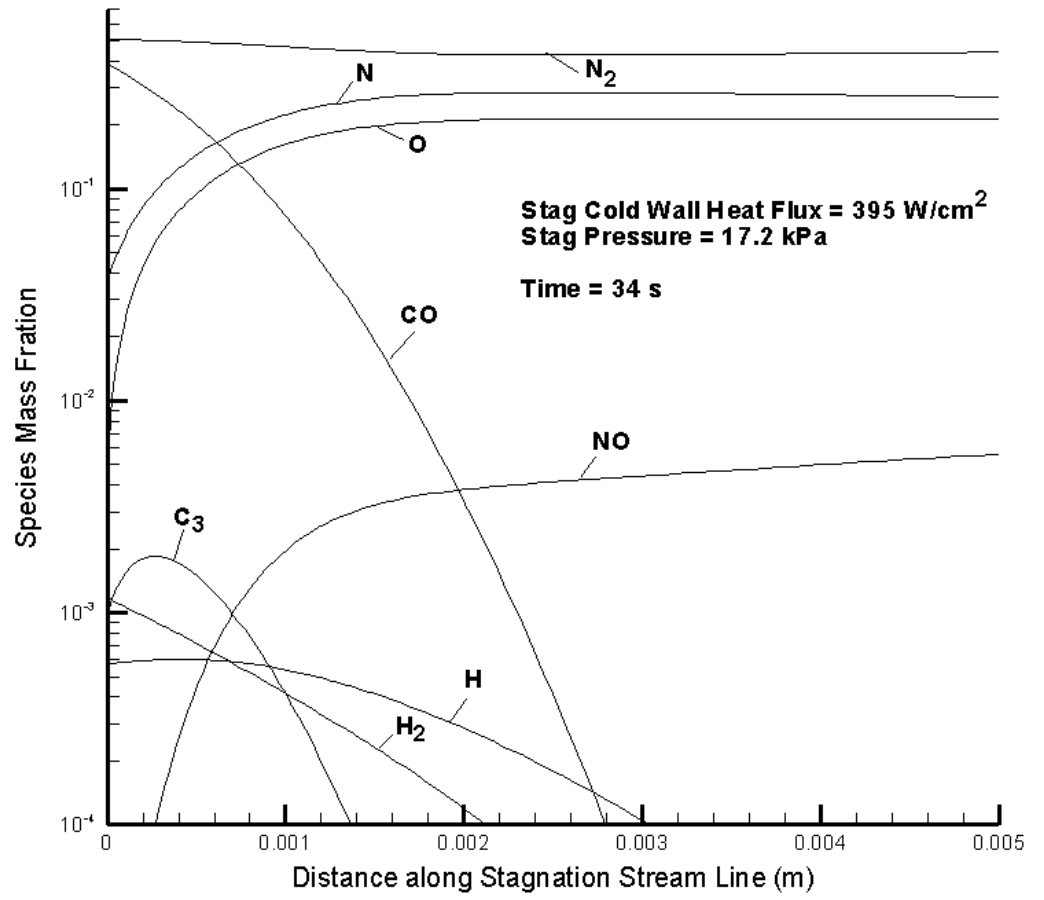

Figure 4c: Species mass fractions along stagnation stream line for case 4.

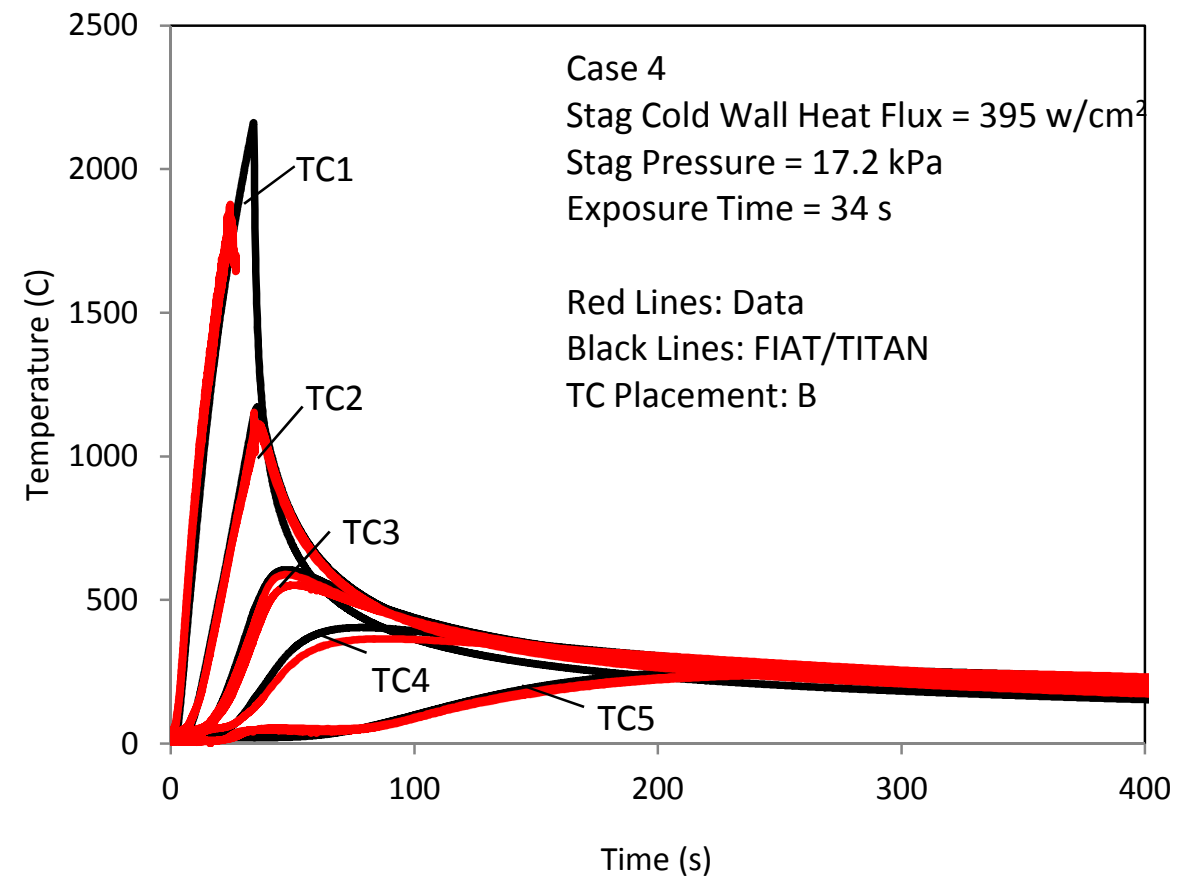

Figure 5: Comparison between prediction and TC data for case 4 using Park's model. 


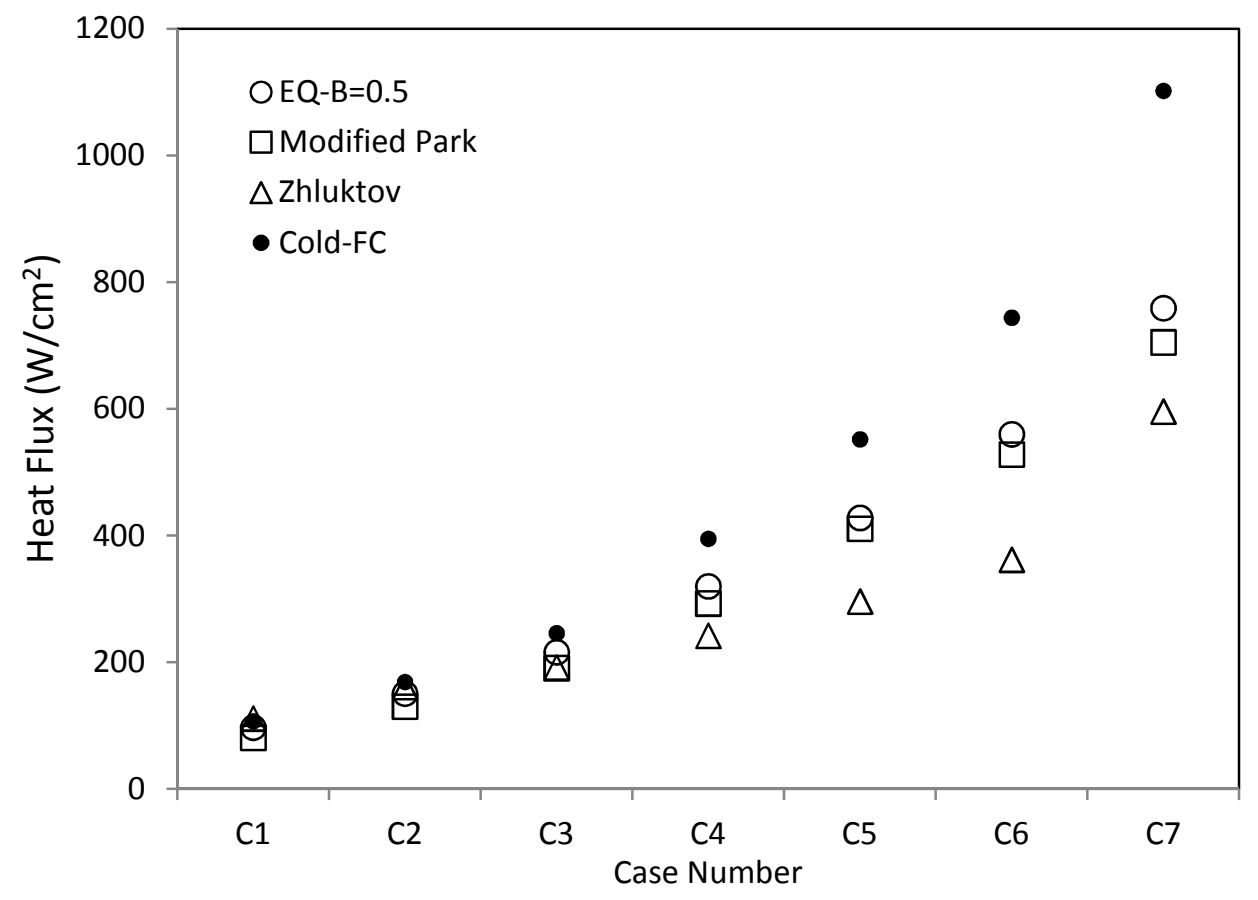

Figure 6a: Stagnation point heat fluxes.

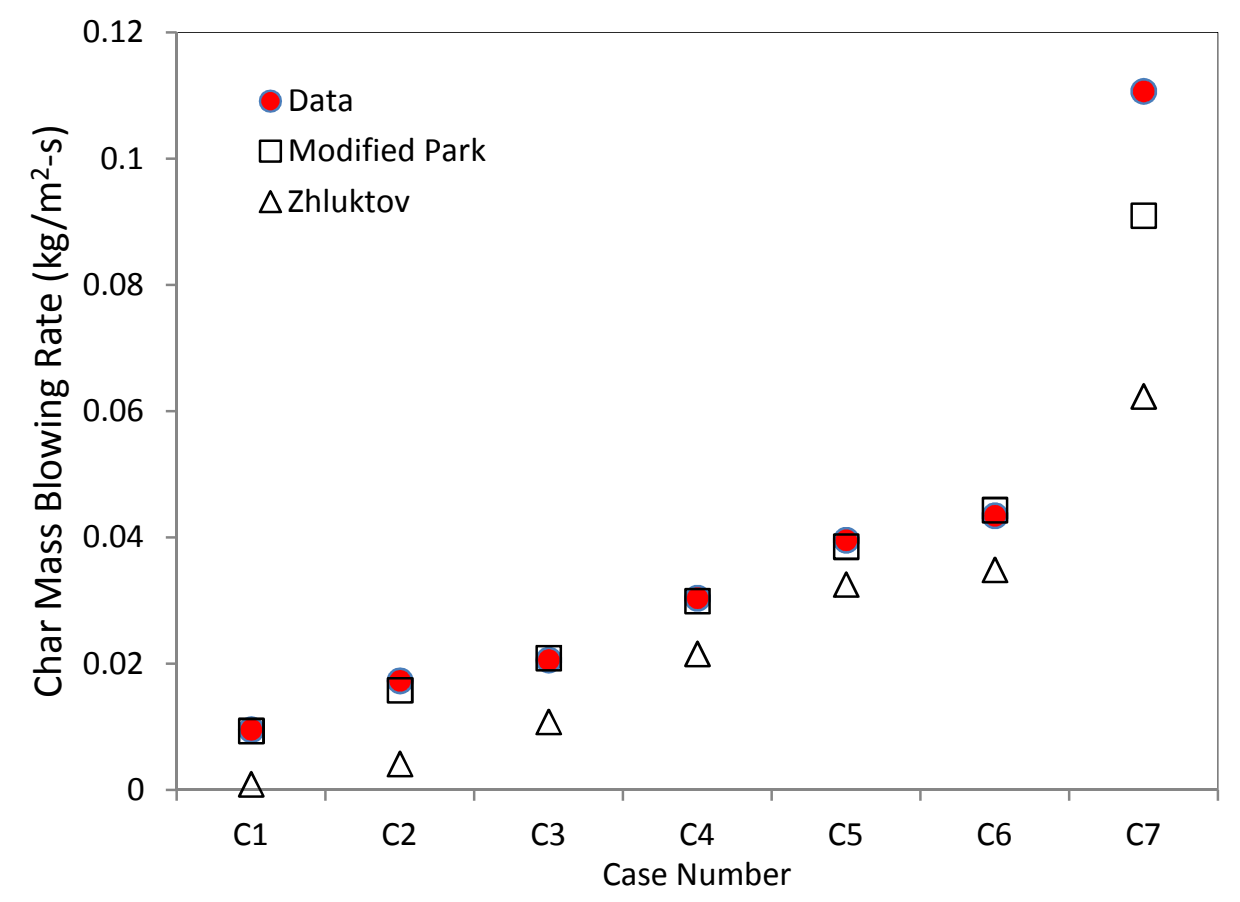

Figure 6b: Stagnation point char mass blowing rates. 


\section{Acknowledgements}

This work is funded by the NASA Fundamental Aeronautics Program Hypersonics Project.

\section{References}

${ }^{1}$ Gökçen, T., Chen, Y.-K., Skokova, K. A., and Milos, F. S., "Computational Analysis of Arc-Jet Stagnation Tests including Ablation and Shape Change," Journal of Thermophysics and Heat Transfer, Vol. 24, No. 4, OctoberDecember 2010, pp 694-707.

${ }^{2}$ Chen, Y.-K., Milos, F. S., and Gökçen, T., "Loosely Coupled Simulation for Two-Dimensional Ablation and Shape Change," Journal of Spacecraft and Rockets, Vol. 47, No 5, September-October 2010, pp. 775-785.

${ }^{3}$ Chen, Y.-K., and Milos, F.S., "Two-Dimensional Implicit Thermal Response and Ablation Program for Charring Materials," Journal of Spacecraft and Rockets, Vol. 38, No. 4, 2001, pp. 473-481.

${ }^{4}$ Wright, M. J., Candler, G. V., and Bose, D., "Data-Parallel Line Relaxation Method for the Navier-Stokes Equations," AIAA Journal, Vol. 36, No. 9, Sept. 1998, pp 1603-1609.

${ }^{5}$ MacLean, M., Marschall, J., and Driver, D., "Finite-Rate Surface Chemistry Model, II: Coupling to Viscous Navier-Stokes Code", AIAA-2011-3784, 42 ${ }^{\text {nd }}$ AIAA Thermophysics Conference, Honolulu, Hawaii, June 27-30, 2011.

${ }^{6}$ Park, C., and Ahn, H. K., "Stagnation-Point Heat Transfer for Pioneer-Venus Probes, " Journal of

Thermophysics and Heat Transfer, Vol. 13, No. 1, January-March 1999, pp. 33-41.

${ }^{7}$ Zhluktov, S. V. and Abe, T., "Viscous Shock-Layer Simulation of Airflow past Ablating Blunt Body with Carbon Surface, " Journal of Thermophysics and Heat Transfer, Vol. 13, No. 1, January-March 1999, pp. 50-59.

${ }^{8}$ Tran, H., Johnson, C, Rasky, D., Hui, F., Chen, Y.-K., and Hsu, M., "Phenolic Impregnated Carbon Ablators (PICA) for Discovery Class Missions," AIAA Paper 96-1911, June 1996.

${ }^{9}$ Chen, Y.-K., and Milos, F. S., " Navier-Stokes Solutions with Finite-Rate Ablation for Planetary Mission Earth Re-entries," Journal of Spacecraft and Rockets, Vol. 42, No. 6, 2005, pp. 961-970.

${ }^{10}$ Anon., User's Manual: Aerotherm Chemical Equilibrium Computer Program, Acurex Corporation, Aerotherm Division, Mountain View, CA, Aug. 1981.

${ }^{11}$ Milos, F.S., and Chen, Y.-K., "Comprehensive Model for Multi-Component Ablation Thermochemistry," AIAA Paper 97-0141, Jan. 1997.

${ }^{12}$ Chen, Y.-K., and Milos, F. S., "Effect of Non-equilibrium Chemistry and Darcy-Forchheimer Flow of Pyrolysis Gas for a Charring Ablator", AIAA-2011-3122, $42^{\text {nd }}$ AIAA Thermophysics Conference, Honolulu, Hawaii, June 27-30, 2011.

${ }^{13}$ Marschall, J., and MacLean, M., "Finite-Rate Surface Chemistry Model, I: Formulation and Reaction System Examples", AIAA-2011-3783, 42 ${ }^{\text {nd }}$ AIAA Thermophysics Conference, Honolulu, Hawaii, June 27-30, 2011.

${ }^{14}$ Milos, F. S., and Chen, Y.-K., "Ablation and Thermal Property Model for Phenolic Impregnated Ablator (PICA)," NASA TM-2009-215377, January 2009.

${ }^{15}$ Olynick, D. R., Chen, Y-K, and Tauber, M. E., "Aerothermodynamics of the Stardust Sample Return Capsule, " Journal of Spacecraft and Rockets, Vol. 36, No. 3, May-June 1999, pp. 442-462.

${ }^{16} \mathrm{Gökçen,} \mathrm{T.,} \mathrm{"N} \mathrm{N}_{2}-\mathrm{CH}_{4}-\mathrm{Ar}$ Chemical Kinetic Model for Simulations of Titan Atmosphere Entry," J. of Thermophysics and Heat Transfer, Vol. 21, No. 1, Jan.-March 2007, pp 9-18.

${ }^{17}$ Kruse, T. and Roth, P., "Kinetics of $\mathrm{C}_{2}$ Reactions during High-Temperature Pyrolysis of Acetylene," J. Phys. Chem. A, 1997, 101, 2138-2146 